http://dx.doi.org/10.1590/1678-4162-9155

Arq. Bras. Med. Vet. Zootec., v.69, n.4, p.793-801, 2017

\title{
Response of three digital anesthetic technics in horses with forelimb hoof lameness
}

\author{
[Resposta de três técnicas anestésicas digitais em equinos com claudicação dos
} membros anteriores ligada ao casco]

\author{
S.L. Dau, M.S. Azevedo, F.D. De La Corte K.E. Brass, M. Gallio, F. Ceni, B.B. Lubini
}

Universidade Federal de Santa Maria - Campus Camobi - Santa Maria, RS

\begin{abstract}
The presented study aimed to assess objectively the response of distal interphalangeal joint (DIJ), navicular bursa (NB) and deep digital flexor tendon sheath (DDFTS) anesthesia in horses with forelimb hoof lameness; and evaluate if the presence of radiographic abnormalities on navicular bone could interfere on blocks' results. Fifteen horses with lameness improvement above 70\% after palmar digital nerve (PDN) block were selected for this study. Blocks were assessed separately on five consecutive trials at seven different time-points. The fifth trial was performed to evaluate the influence of exercise on preexisting lameness. Most of horses $(73.33 \%)$ presented pain related to the podotrochlear apparatus based on clinical and lameness exam and blocks' responses. NB and DIJ anesthesia differed on the frequency of horses with lameness improvement above $70 \%$ only at $10 \mathrm{~min}(\mathrm{p}=0.03)$, and both differed from DDFTS block until $30^{\prime}(\mathrm{p}<0.05)$. The blocks' response was variable along the time and the highest means for NB, DIJ and DDFTS were observed at 5-10 minutes ('), 15$20^{\prime}$ and $10-15^{\prime}$ respectively.Exercise had low interference on lameness intensity since no improvement above $50 \%$ was observed and an increase on lameness intensity over time was identified in seven horses. Variable grades of navicular bone radiographic lesions were observed in 14 horses, although these lesions had no interference on blocks' response ( $p>0.05$ ). The NB and DIJ blocks had similar responses and both were superior to DDFTS anesthesia, coincident with a major prevalence of podotroclear apparatus abnormalities in this equine population.
\end{abstract}

Keywords: chronic lameness, navicular disease, palmar digital nerve block, osteoarthritis, deep digital flexor tendon sheath anesthesia

\section{RESUMO}

O presente estudo avaliou, de forma objetiva, as respostas do bloqueio da articulação interfalangeana distal (AID), da bursa do navicular (BN) e da bainha do tendão flexor digital profundo (BTFDP) em equinos com claudicação ligada ao casco nos membros torácicos; além de analisar a influência das alterações radiográficas do osso navicular no resultado dos bloqueios. Quinze cavalos, que apresentaram uma melhora da claudicação acima de 70\% após o bloqueio do nervo digital palmar, foram selecionados para este estudo. $O s$ bloqueios foram avaliados separadamente em cinco turnos consecutivos e em sete tempos diferentes. $O$ quinto turno foi utilizado para analisar a influência do exercício sobre a claudicação preexistente. A maioria dos cavalos $(73,33 \%)$ apresentou dor relacionada à porção palmar do casco, com base nos achados do exame clínico em movimento e nas respostas dos bloqueios. As anestesias da BN e da AID apresentaram diferença quanto à frequência de cavalos com melhora da claudicação acima de $70 \%$ apenas aos 10min ( $\mathrm{p}=0.03), e$ ambos diferiram do bloqueio da BTFDP até os $30 \mathrm{~min}(\mathrm{p}<0.05)$. A resposta dos bloqueios foi variada ao longo do tempo, e as maiores médias de melhora da claudicação para os bloqueios BN, AID e BTFDP foram observadas aos 5-10min, 15-20min e 10-15min, respectivamente. O exercício teve pequena interferência na intensidade da claudicação, uma vez que nenhuma melhora acima de $50 \%$ foi observada e sete cavalos aumentaram a intensidade da claudicação ao longo do tempo. A presença de diferentes graus de lesão radiográfica do osso navicular foi observada em 14 cavalos, porém essas lesões não interferiram na resposta dos bloqueios ( $p>0,05)$. Os bloqueios da BN e da AID apresentaram respostas semelhantes, e ambos foram superiores ao bloqueio da BTFDP, coincidindo com uma marcada prevalência de doença do aparato podotroclear nesta população de equinos.

Palavras-chave: claudicação crônica, bloqueio do nervo palmar digital, osteoartrite, anestesia da bainha do tendão flexor digital profundo

Recebido em 5 de setembro de 2016

Aceito em 30 de setembro de 2016

E-mail: stefanodau@hotmail.com 


\section{INTRODUCTION}

The hoof is an important structure of the equine locomotor system since it is involved in onethird of chronic forelimb lameness in horses of different equestrian specialties (Murray et al., 2006). The palmar digital nerve (PDN) block is a diagnostic procedure routinely used to identify pain related to the hoof (Schumacher et al., 2014). However, a positive response to this block is not specific, allowing a variety of diagnoses (Parkes et al., 2015). The distal interphalangeal joint (DIJ), navicular bursa (NB) and deep digital flexor tendon sheath (DDFTS) anesthesia technics are usually employed in attempt to identify pain source in the hoof more precisely (Turner, 1996; Schumacher et al., 2014), and help to evaluate the significance of lesions identified on imaging exams (Dyson \& Kidd, 1993). However, NB and DIJ blocks present undesirable effects over other structures of the hoof due the diffusion of anaesthetic agents between synovial structures (Pleasant et al., 1997; Gough et al., 2002; Schumacher et al., 2003) or to palmar digital nerves (Schumacher et al., 2000; Schumacher et al., 2001a; Seabaugh et al., 2011). The DDFTS anesthesia is considered a more specific block than NB and DIJ block, since this block has low effect on lameness related to other structures within the hoof (Harper et al., 2007) and it presents low diffusion of anesthetic to the surrounding structures (Jordana et al., 2014).

The majority of studies that have been performed to assess responses of digital anaesthesia techniques utilized a subjective evaluation criteria (Dyson \& Kidd, 1993; Pleasant et al., 1997; Schumacher et al., 2000; Schumacher et al., 2001a; Harper et al.,2007; Parkes et al.,2015), which presents limiting factors such as clinician experience (Keegan et al., 1998), tendency of bias (Arkell et al., 2006), and the difficulty to assess mild lameness cases even for more experienced clinicians (Keegan et al., 2010). Furthermore, most of those studies were performed using induction of lameness by creating a painful stimulus in a specific portion/structure in the hoof different from what happens in clinical cases in which there is usually more than one structure involved (Gutierrez-Nibeyro et al., 2007; Parkes et al., 2015).
The aim of the present study was to objectively assess the responses of DIJ, NB and DDFTS anesthesia technics in horses with forelimb hoof lameness, and evaluate if the presence of radiographic abnormalities on navicular bone could interfere on blocks' response.

\section{MATERIALS AND METHODS}

The Committee on Animal Research and Ethics from Federal University of Santa Maria approved the present study (protocol number CEUA 2136230315). Fifteen (three mares and twelve geldings) out of 50 horses examined, of different breeds and sport disciplines, presenting forelimb hoof lameness were selected. The selection criterion for this study was an improvement on lameness of $70 \%$ or higher at 5,10 or 15 minutes (') after a PDN block according to objective evaluation. Horses aged from 4 to 18 years $(13 \pm 5$ years) and weighed between 380 and $5201 \mathrm{~kg}$ $(455 \pm 43 \mathrm{~kg})$.

The lameness evaluation began by inspection and palpation of distal forelimbs, evaluating hoof conformation, response to hoof tester and forced distal limb flexion, presence of DIJ and DDFTS effusion and reaction to DIJ medial/lateral torque. Thereafter, all horses were equipped with a body-mounted inertial sensor system (Lameness Locator ${ }^{\mathrm{TM}}$, Equinosis®LLC, USA), as previously described (Keegan et al., 2012), for objective motion exam which was performed by trotting horses in a straight line over a flat hard surface (asphalt or concrete) to collect a baseline of at least 30 strides to compare with block's responses. A second baseline of 10-15 strides was recorded to compare with the response of distal limb flexion test performed on both forelimbs before the PDN block. A subjectively exam based on AAEP (1991) grade system was also performed while recording baseline before blocks.

The system utilized for objective evaluation was composed by two accelerometers attached on the midline of sacral tuberosities and on poll region and by one gyroscope fixed on the dorsal aspect of right forelimb pastern. Accelerometers measure the vertical movement of head and pelvis and it allow calculation of the mean difference $( \pm S D)$ of maximum and minimum height of head (HDmax and HDmin) and pelvis (PDmax and PDmin) after the stance phase 
between contralateral fore and hind limbs respectively, and the gyroscope works as a marker to determine lameness' side based on the stance phase of right forelimb movement. The Vector Sum (VS) represents forelimb lameness intensity, which is measured by the formula: $\sqrt{H D \max ^{2}+H D \min ^{2}}$ (Lameness Locatoruser manual). Only values related to forelimbs were utilized in the present study, therefore lameness was considered when HDmax and/or HDmin were above $6 \mathrm{~mm}$ and higher than standard deviation (SD), and the VS over $8.5 \mathrm{~mm}$. Lameness improvement was calculated as a percentage using the formula: $\left(\mathrm{VS}_{\text {before block }}-\right.$ $\left.\mathrm{VS}_{\text {after block}}\right) /\left(\mathrm{VS}_{\text {before block }}\right)$ (Lameness Locatoruser manual). Horses that switch lameness for the contralateral forelimb after block were diagnosed with bilateral lameness and an improvement of $100 \%$ was considered.

Blocks were performed one per trial with at least eight hour intervals after the last evaluation of the previous block. The response of each block was assessed in seven different time-points: before, and at 5, 10, 15, 20, 30 and $60^{\prime}$ after injection. The PDN block was performed on the first trial to select horses with hoof pain and it was also evaluated during all time-points to be used as a positive control. The DIJ, NB and DDFTS blocks were performed randomly among second, third and fourth trial. In addition, all horses were evaluated in a fifth trial without any block to assess the influence of exercise over preexisting lameness. Each horse was handled by the same person during all times and trials. Aseptic preparation with povidone-iodine and $70^{\circ}$ alcohol proceeded all blocks. A tranquilization with $0.025 \mathrm{mg} / \mathrm{kg}$ of acepromazine was used for those horses with restless behavior to facilitate the procedure and to improve data collection by the system (Azevedo et al., 2015).

The PDN block was performed using $1.5 \mathrm{~mL}$ of $2 \%$ lidocaine with a $26 \mathrm{G}$ needle inserted in a medial to distal direction proximal to ungular cartilage (Seabaugh et al., 2011). The block's effect was evaluated by testing the heel sensation with a blunt object before evaluation at 5 '. Anesthesia of DIJ was performed by dorsal lateral approach with a $23 \mathrm{G} 1$ " needle using $5 \mathrm{~mL}$ of $2 \%$ lidocaine, and the correct needle placement was confirmed by no resistance to injection or by reflux of synovial fluid out of the needle hub (Dyson, 1991). Navicular bursa block was performed with $3 \mathrm{~mL}$ of $2 \%$ lidocaine and $0.5 \mathrm{~mL}$ of a positive contrast medium (Ominopaque ${ }^{\circ}$, Iohexol, GE Healthcare (Shanghai) Co., Ltd, China) with a 19G 3.5-inch spine needle by distal palmar approach to the navicular position (Schramme et al., 2000), and the correct needle position was confirmed by lateromedial radiographs and presence of contrast in the NB. A palmar approach at the mid-pastern level with the limb flexed and suspended was used to block DDFTS; $5 \mathrm{~mL}$ of $2 \%$ lidocaine was injected using a $24 \mathrm{G} 3 / 4$ " needle perpendicular to the skin, and injection with no resistance, or presence of fluid on needle hub, was used as reference for correct needle placement; skin sensation was tested to evaluate palmar digital nerve desensitization (Jordana et al., 2014) at 5'.

Radiographic exams were performed on the same trial of NB block using the following projections to evaluate the navicular bone: lateralmedial, dorsalpalmar, dorso65 ${ }^{\circ}$ proximal-palmarodistal oblique, dorso $45^{\circ}$ lateral-palmaromedial oblique, dorso $45^{\circ}$ medial-dorsolateral oblique and palmaro $45^{\circ}$ proximal-palmarodistal oblique (navicular skyline) (Dyson, 2008; Turner, 2013). Horses were grouped according to the grade of navicular bone lesion as grade I (GI): good navicular bone condition associated with less than six lucent zones along the distal border; grade II (GII): slight definition between the palmar cortex and the medulla, up to 8 lucent zones distributed on the distal horizontal border and mild entheseophyte formation on the proximal border of navicular bone; grade III (GIII) poor corticomedullary definition, thickening of dorsal and flexor cortices, more than 7 radiolucent zones along distal and proximal border, large entheseophyte formation on the proximal border and discrete mineralization of collateral ligament of the navicular bone; and grade IV (GIV): large cystlike lesion within the medulla, poor corticomedullary definition and new bone formation on the flexor cortex (Dyson, 2008).

The frequency of horses (\%) with lameness improvement higher than $50 \%$ and $70 \%$ after each block was compared over time by Fischer's exact test. The means of LI according to navicular bone group were compared by the 
nonparametric Kruskal-Wallis test after the Shapiro-Wilk normality test. The basal VS means before each block were compared by the Friedman test. All tests were performed with significance set at $\mathrm{p}<0.05$ (GraphPad Prism version 5.00, San Diego, California, USA).

\section{RESULTS}

The physical exam with hoof tester revealed the palmar $(66.66 \%)$ and dorsal sole region $(33.33 \%)$ as the most painful portions of the hoof. A positive response to distal limb flexion was observed in 14/15 horses. Effusion of DIJ and DDFTS was observed in nine $(60 \%)$ and four (26.66\%) horses, respectively. Long toe was the most common hoof conformation abnormality observed $(66.66 \%)$ and, $70 \%$ of these horses had a negative palmar angle of third phalanx confirmed by the latero-medial radiographs.

Unilateral or bilateral preexisting lameness was observed in five $(33.33 \%)$ and ten $(66.66 \%)$ horses respectively. A grade III out of $\mathrm{V}$ (Guide..., 1991) of lameness was observed in all horses at baseline evaluation during the five trials. Furthermore, no difference $(p=0.4093)$ was observed among VS means of control, PDN, DDFTS, NB and DIJ blocks at baseline, and their

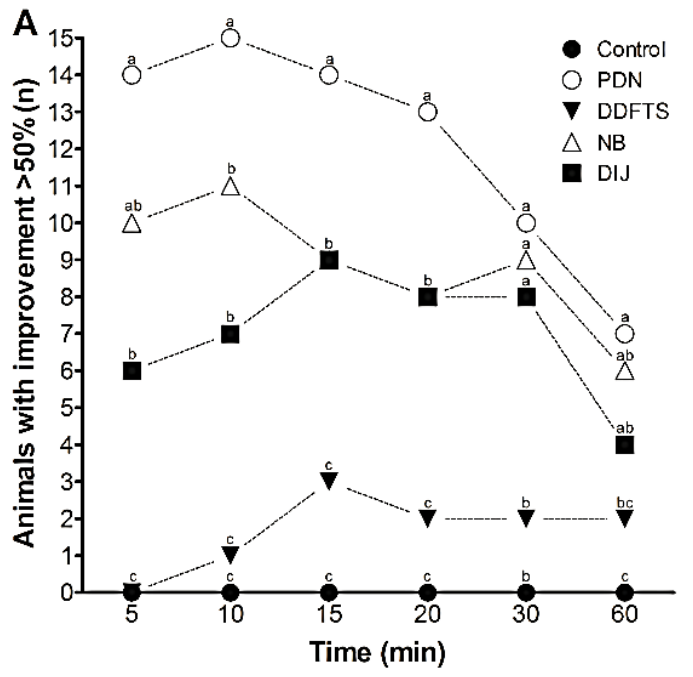

means and SD $( \pm)$ were respectively: $54.25 \mathrm{~mm}$ $( \pm 36.72), 48.58 \mathrm{~mm}( \pm 31.23), 49.25 \mathrm{~mm}( \pm 25.26)$, $45.24 \mathrm{~mm}( \pm 23.14)$ and $45.20 \mathrm{~mm}( \pm 26.17)$. An increase on lameness to grade IV (Guide..., 1991) could be observed on the trial after NB block in some horses, and a wider interval of 1224 hours was necessary to horses return to the same lameness intensity (VS) observed before NB block.

The NB and DIJ anesthesia presented similar responses when evaluating the frequency of horses with lameness improvement higher than 50 or $70 \%$, although the NB block was more efficient in improving lameness above $70 \%$ than DIJ block at 10min $(\mathrm{p}=0.03)$ (Figure A-B). Deep digital flexor tendon sheath anesthesia (DDFTS) was the least effective block of the three technics tested, since lameness improvement higher than $70 \%$ was not observed at any time. Only three horses presented a lameness improvement above $50 \% 15$ ' after DDFTS block, and this block presented similar efficacy to $\mathrm{NB}(\mathrm{P}=0.0898)$ and DIJ ( $\mathrm{P}=0.2414)$ block only at 60' (Figure 1A). However, only the NB analgesia presented similar efficacy to PDN block at 5' $(\mathrm{p}=0.23)$ and $10^{\prime} \quad(\mathrm{p}=0.07)$ when evaluating lameness improvement higher than $70 \%$ (Fig. 1B).

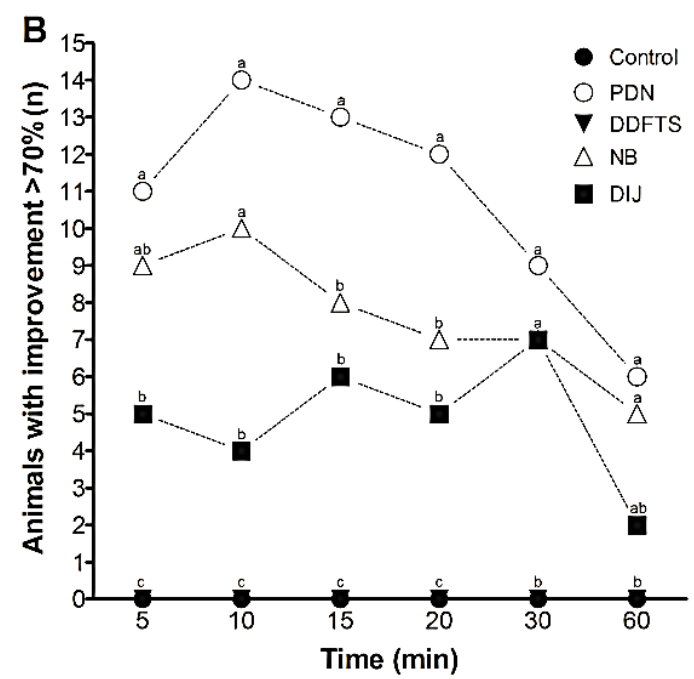

Figure 1. Number of horses (y-axis) with improvement of hoof lameness higher than 50\% (A), or 70\% (B), in different time-points (x-axis) after palmar digital nerve (PDN), deep digital flexor tendon sheath (DDFTS), navicular bursa (NB) and distal interphalangeal joint (DIJ) blocks or without any block (Control). Difference on the number of animals is represented by different letters at each time point $(\mathrm{P}<0.05)$ 
The highest improvement rates for NB block were at $5(70 \% \pm 35)$ and $10 \%(72 \% \pm 36)$, for DIJ anesthesia were at $15(59 \% \pm 34)$ and 20 ' $(56 \% \pm 35)$, and for DDFTS analgesia at $10(25 \%$ $\pm 20)$ and $15,(26 \% \pm 20)$ (Figure 2$)$. Horses with better responses to DDFTS anesthesia had some degree of effusion in the DDFTS. From the 15 horses that improved more than $50 \%$ with PDN, 11 improved at the same rate after DIJ. As for the other 4 horses, two improved $100 \%$ after NB block and two did not improve more than $50 \%$ with no other block.

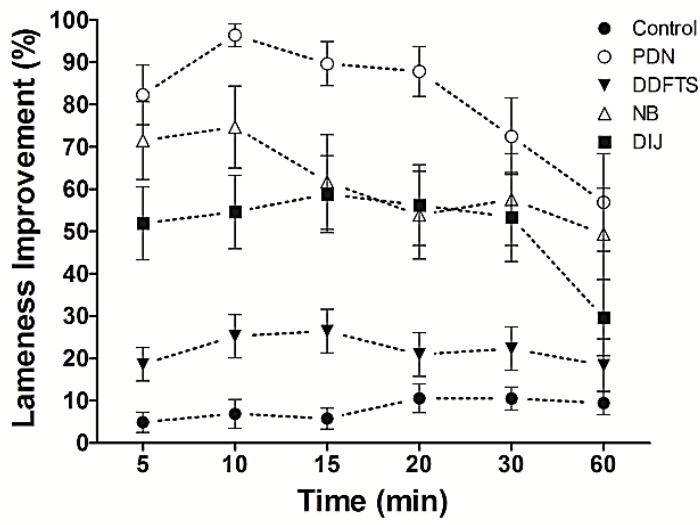

Figure 2. Lameness improvement means (y-axis) and standard error $( \pm \mathrm{SE})$ of blocks evaluated in different time-points (x-axis) in horses with forelimb hoof lameness. PDN: palmar digital nerve block; DDFTS: deep digital flexor tendon sheath block; NB: navicular bursa block; and DIJ: distal interphalangeal block.

Table 1. Distribution (n) of 14 horses with lameness improvement (LI) above $50 \%$ or $70 \%$ after navicular bursa (NB) distal interphalangeal joint (DIJ) and deep digital flexor tendon sheath (DDFTS) blocks associated to the different degrees of navicular bone radiographic lesions

\begin{tabular}{|c|c|c|c|c|c|c|c|c|c|c|}
\hline \multirow{4}{*}{ LI } & \multirow{4}{*}{$\begin{array}{l}\text { Blocks' } \\
\text { response }\end{array}$} & \multicolumn{8}{|c|}{ Navicular Bone lesions } & \multirow{4}{*}{ Total } \\
\hline & & \multirow{2}{*}{\multicolumn{2}{|c|}{$\begin{array}{c}\text { GI }(n=4) \\
\text { DDFTS }\end{array}$}} & \multirow{2}{*}{\multicolumn{2}{|c|}{$\begin{array}{c}\text { GII }(n=5) \\
\text { DDFTS }\end{array}$}} & \multirow{2}{*}{\multicolumn{2}{|c|}{$\begin{array}{c}\text { GIII }(n=3) \\
\text { DDFTS }\end{array}$}} & \multirow{2}{*}{\multicolumn{2}{|c|}{$\begin{array}{c}\text { GIV }(\mathrm{n}=2) \\
\text { DDFTS }\end{array}$}} & \\
\hline & & & & & & & & & & \\
\hline & & $<50 \%$ & $>50 \%$ & $<50 \%$ & $>50 \%$ & $<50 \%$ & $>50 \%$ & $<50 \%$ & $>50 \%$ & \\
\hline \multirow{5}{*}{$\begin{array}{l}50- \\
70 \%\end{array}$} & $\begin{array}{c}\mathrm{NB}(+) ; \mathrm{DIJ} \\
(+)\end{array}$ & 3 & 1 & 2 & 1 & 1 & - & 1 & 1 & 10 \\
\hline & $\begin{array}{c}\mathrm{NB}(+) ; \mathrm{DIJ} \\
(-)\end{array}$ & - & - & 1 & - & 0 & - & - & - & 1 \\
\hline & $\begin{array}{c}\text { NB (-); DIJ } \\
(+)\end{array}$ & - & - & - & - & 1 & - & - & - & 1 \\
\hline & $\begin{array}{c}\text { NB (-); DIJ } \\
(-)\end{array}$ & - & - & 1 & - & 1 & - & - & - & 2 \\
\hline & Total & 3 & 1 & 4 & 1 & 3 & 0 & 1 & 1 & 14 \\
\hline \multirow{5}{*}{$>70 \%$} & $\begin{array}{c}\mathrm{NB}(+) ; \text { DIJ } \\
(+)\end{array}$ & 1 & 1 & 2 & - & - & - & 1 & 1 & 6 \\
\hline & $\begin{array}{c}\mathrm{NB}(+) ; \text { DIJ } \\
(-)\end{array}$ & 2 & - & 1 & - & 1 & - & - & - & 4 \\
\hline & $\begin{array}{c}\text { NB (-); DIJ } \\
(+)\end{array}$ & - & - & - & 1 & 1 & - & - & - & 2 \\
\hline & $\begin{array}{c}\text { NB (-); DIJ } \\
(-)\end{array}$ & - & - & 1 & - & 1 & - & - & - & 2 \\
\hline & Total & 3 & 1 & 4 & 1 & 3 & 0 & 1 & 1 & 14 \\
\hline
\end{tabular}


The exercise demonstrated low interference in reducing lameness over time, since no improvement above $50 \%$ was observed (Figure 1A). On the other hand, an increase on lameness was observed in seven horses $(46.66 \%)$ at alltime points and the highest increases of VS compared to baseline value were observed at 10 $(8.97 \mathrm{~mm} \pm 6.83)$ and $15^{\prime}(9.29 \mathrm{~mm} \pm 7.62)$. Eight horses $(53.33 \%)$ presented a slight improvement on lameness, which was observed in three horses with unilateral and five with bilateral lameness.

Radiographic exam pointed out different grades of damage on navicular bone in 14 horses of the study $(\mathrm{GI}=4$; GII $=5 ; \mathrm{GIII}=3 ; \mathrm{GIV}=2)$, and lesions on the distal interphalangeal joint could also be observed in six of them. No difference on block's response was observed comparing groups of navicular bone lesion $(\mathrm{P}>0.05)$ (Tab. 2) Two horses with grade IV of navicular bone lesion, one with acute and other with chronic lameness presented similar responses for DIJ and NB blocks. However, a higher lameness improvement was observed after DDFTS in the horse with chronic lameness $(51.56 \% \pm 15.65)$ than that with acute lameness $(13.35 \% \pm 6.74)$ over time.

Table 2. Mean $( \pm \mathrm{SD})$ of lameness improvement $(\%)$ after deep digital flexor tendon sheath (DDFTS), navicular bursa (NB) and distal interphalangeal joint (DIJ) blocks in horses with grade I $(n=4)$, II $(n=5)$ and III/IV $(n=5)$ of navicular bone radiographic lesions over time $(\mathrm{p}>0.05)$

\begin{tabular}{|c|c|c|c|c|c|c|c|c|c|}
\hline \multirow{3}{*}{ Time } & \multicolumn{9}{|c|}{ Block } \\
\hline & & NB & & & DIJ & & & DDFTS & \\
\hline & GI & GII & GIII+GIV & GI & GII & GIII+GIV & GI & GII & GIII+GIV \\
\hline 5 & $60.88( \pm 42)$ & $80.55( \pm 27)$ & $63,37( \pm 43)$ & $61.18( \pm 32)$ & $39.43( \pm 41)$ & $58,4( \pm 33)$ & $12.23( \pm 21)$ & $31.52( \pm 4)$ & $18,4( \pm 7)$ \\
\hline 10 & $94.46( \pm 11)$ & $61.98( \pm 42)$ & $42,7( \pm 42)$ & $73.12( \pm 32)$ & $31.50( \pm 30)$ & $32,54( \pm 34)$ & $13.35(23)$ & $33.38( \pm 10)$ & $7,162( \pm 21)$ \\
\hline $15^{\prime}$ & $55.32( \pm 52)$ & $56.23( \pm 43)$ & $59,44( \pm 43)$ & $80.93( \pm 22)$ & $41.23( \pm 44)$ & $64,04( \pm 29)$ & $15.08( \pm 28)$ & $35.31( \pm 12)$ & $31,61( \pm 15)$ \\
\hline 20 & $53.52( \pm 54)$ & $51.60( \pm 41)$ & $42,28( \pm 34)$ & $73.17( \pm 32)$ & $39.57( \pm 43)$ & $34,32( \pm 32)$ & $10.12( \pm 20)$ & $22.02( \pm 16)$ & $21,25( \pm 24)$ \\
\hline 30 & $83.77( \pm 32)$ & $31.88( \pm 46)$ & $60,38( \pm 36)$ & $70.47( \pm 35)$ & $36.63( \pm 46)$ & $65,53( \pm 39)$ & $8.51( \pm 14)$ & $26.81( \pm 17)$ & $31,87( \pm 23)$ \\
\hline $60^{\prime}$ & $77.19( \pm 46)$ & $10.68( \pm 21)$ & $43,45( \pm 28)$ & $9.74( \pm 11)$ & $37.64( \pm 43)$ & $29,07( \pm 39)$ & $2.25( \pm 4)$ & $15.67( \pm 17)$ & $15,01( \pm 31)$ \\
\hline
\end{tabular}

\section{DISCUSSION}

The meaningful point of the present study was the possibility to objectively evaluate the response of different hoof anesthesia techniques, yielding a more precise evaluation regardless of any variations on individual experience and free of bias (Arkell et al., 2006; Keegan et al., 2010). Some variables such as lameness intensity, hoof shoeing quality and lameness duration were not possible to control as they occur in many clinical studies. However, the experimental design assessing hoof blocks' results from clinical cases at different moments proved to be reliable once baseline VS mean from each trial were not different $\quad(p=0.4093)$. The podotrochlear apparatus was considered as the major pain source for most horses of this study (11/15) based on response to hoof tester, presence of radiographic lesions on the navicular bone (14/15), and best block's responses was achieved after the NB block (11/15) (Schumacher et al., 2003). However, lesions on DDFT and suspensory ligaments of navicular bone were not ruled out as primary or as additional source of pain, since most cases of hoof lameness more than one structure is involved as demonstrated in MRI studies (Dyson et al. 2003; GutierrezNibeyro et al., 2007). Although, DDFT was not considered as a primary pain source since PDN and NB blocks eliminated lameness in almost all cases, in contrast to what was describe for horses with DDFT as primary pain source, which improved at higher rate with DIJ and NB analgesia than after PDN block (Dyson et al., 2003).

In this population of horses, anesthesia of NB and DIJ demonstrated similar efficacy based on horses with lameness improvement above 50 or $70 \%$ overtime (Fig.1A-B). In spite of that, the higher means of improvement for NB block were observed at 5 and 10', and for DIJ analgesia at 15 and 20' (Fig.2). This later response of DIJ anesthesia could be explained by the source of pain been centered in the podotrochlear apparatus, and less likely to be related to the coffin joint primarily, which require more time to anesthetic diffuse from joint to the PDN or NB (Schumacher et al., 2001b). Moreover, the 
presence of radiographic lesions on navicular bone could have also interfered negatively with lidocaine diffusion as described for triamcinolone (Manfredi et al., 2012). Those findings could explain the difference of time and response observed for DIJ block in the present study to other study using horses with lameness caused by induction of navicular bursitis in healthy horses (Pleasant et al., 1997), and in another with mild hoof lameness cases (Dyson \& Kidd, 1993). Another study demonstrated objectively that 10 of 22 horses with lameness on the distal portion of the forelimb had equivalent DIJ and PDN responses at 10' (Rungsri et al., 2014). The difference from this to the presented study could be explained by the source of pain, since horses of that study presented a better response after the abaxial nerve block demonstrating that pain source was not centered within to the hoof.

The DDFTS block demonstrated lower frequency of lameness improvement compared to NB and DIJ blocks $(\mathrm{p}<0.05)$ (Fig. 1A-B). The reduced rate of improvement observed could be associated to the absence of DDFT lesions since anesthesia of DDFTS has low effect on lameness related to other structures of the hoof (Harper et al., 2007). The small dose $(0.5 \mathrm{~mL}$ of lidocaine $/ 50 \mathrm{~kg}$ ) utilized compared to the dose of $1 \mathrm{~mL} / 50 \mathrm{~kg}$ reported in the literature (Harper et al., 2007; Jordana et al., 2014) could also explain the low improvement rate observed after DDFTS in the present study. It suggested a possible dose effect for DDFTS anesthesia. This anaethesia technique should be applied more frequently on lameness exam to identify DDFT lesions when a specific exam as MRI is not available, since this structure is correlated to poor treatment response and prognosis, (Dyson et al., 2003; GutierrezNibeyro et al., 2007).

Time factor demonstrated to be important when evaluating blocks' response based on the lameness improvement rates identified (Fig.2), since most specific results were observed on the first 5 to $10^{\prime}$ post injection; after that time NB block rates decreased, DIJ and DDFTS anesthesia rates increased. This variability of blocks' responses could be explained due to diffusion or leakage of anesthetic agent (Gough et al., 2002; Seabaugh et al., 2011, Jordana et al., 2014) which make the response less accurate over time (Schumacher et al., 2001a; Schumacher et al., 2003).

Lameness improvement rates higher than 50\% were observed until 30' after PDN, NB and DIJ anesthesia with lidocaine (Fig. 2), therefore an overlap of blocks' effect may happen using those blocks in a short time interval. In addition, an increase of blocks' maximum rates duration may be observed using long acting anesthetics agents, such as bupivacaine, as observed in PDN block (Silva et al., 2015). Although a more specific response probably would still be evident at 5 to 10 ' post injection. For that reason, hoof blocks should be used on different moments when possible (Dyson and Kidd, 1993) to achieve a more accurate diagnose, such as to differ navicular pain from heel pain (Turner, 1996). The authors believe that there is not a correct sequence to perform hoof blocks as previously described (Dyson \& Kidd, 1993; Turner,1996), therefore clinicians should execute them based on the clinical examination findings for each case, and start with the block that desensitizes a reduced number of structures such as the DDFTS block (Pleasant et al., 1997).

\section{CONCLUSION}

The results of this study demonstrated that NB and DIJ blocks have similar response and both are more efficient than DDFTS block in improving lameness of horses with forelimb hoof pain, associated with a major prevalence of podotroclear apparatus in this equine population.

\section{REFERENCES}

ARKELL, M.; ARCHER, R.M.; GUITIAN, F.J.; MAY, S.A. Evidence of bias affecting the interpretation of the results of local nerve blocks when assessing lameness in horses. Vet. Rec., v.159, p.346-349, 2006.

AZEVEDO, M.S.; DE LA CÔRTE, F.D.; BRASS, K.E. et al. The use of xylazine or acepromazine does not interfere in the lameness evaluation by inertial sensors. J. Equine Vet. Sci., v.35, p.27-30, 2015.

DYSON, S.J. Lameness due to pain associated with the distal interphalangeal joint: 45 cases. Equine Vet. J., v.23, p.128-135, 1991. 
DYSON, S.J. Radiological interpretation of the navicular bone. Equine Vet. Educ., v.20, p.268280, 2008.

DYSON, S.J.; KIDD, L. A comparison of responses to analgesia of the navicular bursa and intra-articular analgesia of the distal interphalangeal joint in 59 horses. Equine Vet. J., v.25, p.93-98, 1993.

DYSON, S.J.; MURRAY, R.; SCHRAMME, M.; BRANCH, M. Lameness in 46 horses associated with deep digital flexor tendonitis in the digit: diagnosis confirmed with magnetic resonance imaging. Equine Vet. J., v.35, p.681$690,2003$.

GOUGH, M.R.; MAYHEW, G.; MUNROE, G.A. Diffusion of mepivacaine betweenadjacent synovial structures in the horse. Part 1: forelimb foot and carpus. Equine Vet. J., v.34, p.80-84, 2002.

GUIDE for veterinary service and judging of equestrian events. 4.ed. Lexington: AAEP, 1991. $149 \mathrm{p}$.

GUTIERREZ-NIBEYRO, S.D.; WHITE II, N.A.; WERPY, N.M. Outcome of medical treatment for horses with foot pain: 56 cases. Equine Vet. J., v.42, p.680-685, 2007.

HARPER, J.; SCHUMACHER, J.; DEGRAVES, F. et al. Effects of analgesia of the digital flexor tendon sheath on pain originating in the sole, distal interphalangeal joint or navicular bursa of horses. Equine Vet. J., v.39, p.535-539, 2007.

JORDANA, M.; MARTENS, A.; DUCHATEAU, L. et al. Distal limb desensitisation following analgesia of the digital flexor tendon sheath in horses using four different techniques. Equine Vet. J., v.46, p.488493, 2014.

KEEGAN, K.G.; DENT, E.V.; WILSON, D.A. et al. Repeatability of subjective evaluation of lameness in horses. Equine Vet. J., v.42, p.92-97, 2010 .

KEEGAN， K.G.; MACALLISTER， C.G.; WILSON, D.A. et al. Comparison of an inertial sensor system with a stationary force plate for evaluation of horses with bilateral forelimb lameness. Am. J. Vet. Res., v.73, p.368-74, 2012.
KEEGAN, K.G.; WILSON, D.A.; WILSON, D.J. et al. Evaluation of mild lameness in horses trotting on a treadmill by clinicians and interns or residents and correlation of their assessments with kinematic gait analysis. Am. J. Vet. Res., v.59, p.1370-1377, 1998.

MANFREDI, J.M.; BOYCE, M.; MALONE, E.D. et al. Steroid diffusion into the navicular bursa occurs in horses affected by palmar foot pain. Vet. Rec., v.171, p.642, 2012.

MURRAY, R.C.; DYSON, S.J.; TRANQUILLE, C.; ADAMS, V. Association of type of sport and performance level with anatomical site of orthopaedic injury diagnosis. Equine Vet. J. Suppl., v.36, p.411-416, 2006.

PARKES, R.; NEWTON, R.; DYSON, S. Is there an association between clinical features, response to diagnostic algesia and radiological findings in horses with a magnetic resonance imaging diagnosis of navicular disease or other injuries of the podotrochlear apparatus? Vet. J., v.204, p.40-46, 2015.

PLEASANT, R.S.; MOLL, H.D.; LEY, W.B. et al. Intra-articular anesthesia of the distal interphalangeal joint alleviates lameness associated with the navicular bursa in horses. Vet. Surg., v.26, p.137-140, 1997.

RUNGSRI, P.K.; STAECKER, W.; LEELAMANKONG, P. et al. Use of bodymounted inertial sensors to objectively evaluate the response to perineural analgesia of the distal limb and intra-articular analgesia of the distal interphalangeal joint in horses with forelimb lameness. J. Equine Vet. Sci., v.34, p.972-977, 2014.

SCHRAMME, M.C.; BOSWELL, J.C.; HAMHOUGIAS, K. et al. An in vitro study to compare 5 different techniques for injection of the navicular bursa in the horse. Equine Vet. J., v.32, p.263-267, 2000.

SCHUMACHER, J.; SCHUMACHER, J.; DE GRAVES, F. et al. A comparison of the effects of local analgesic solution in the navicular bursa of horses with lameness caused by solar toe or solar heel pain. Equine Vet. J., v.33, p.386-389, 2001a. 
SCHUMACHER, J.; SCHUMACHER, J.; DE GRAVES, F. et al. A comparasion of the effects of two volumes of local analgesic solution in the distal interphalangeal joint of horses with lameness caused by solar toe or solar heel pain. Equine Vet. J., v.33, p.265-268, 2001 b.

SCHUMACHER, J.; SCHUMACHER, J.; GILLETTE, R. et al. The effects of local anaesthetic solution in the navicular bursa of horses with lameness caused by distal interphalangeal joint pain. Equine Vet. J., v.35, p.502-505, 2003.

SCHUMACHER, J.; SCHUMACHER, J.; SCHRAMME, M.; MOYER, W. Review of mistakes that can be made when interpreting the results of diagnostic analgesia during a lameness examination. AAEP Proc., v.60, p.83-92, 2014.

SCHUMACHER, J.; STEIGER, R.; SCHUMACHER, J. et al. Effects of analgesia of the distal interphalangeal joint or palmar digital nerves on lameness caused by solar pain in horses. Vet. Surg., v.29, p.54-58, 2000.
SEABAUGH, K.A.; SELBERG, K.T.; VALDES-MARTINEZ, A. et al. Assessment of the tissue diffusion of anesthetic agent following administration of a low palmar nerve block in horses. J. Am. Vet. Med. Assoc., v.239, p.13341340, 2011.

SILVA, G.B.; DE LA CÔRTE, F.D.; BRASS, K.E. et al. Duration and efficacy of different local anesthetics on the palmar digital nerve block in horses. Equine Vet. J., v.35, p.749-755, 2015.

TURNER, T.A. Predictive value of diagnosis tests for navicular pain. In: AMERICAN ASSOCIATION EQUINE PRACTITIONERS ANNUAL CONVENTION, 42., 1996, Denver. Proceedings... Denver: AAEP, 1996. p.201-204.

TURNER, T.A. Routine imaging of the equine foot. In: AMERICAN ASSOCIATION EQUINE PRACTITIONERS FOCOUS ON THE FOOT MEETING, 2013, Fort Collins. Proceeding... Fort Collins: AAEP, 2013. p.18-23. 